\title{
OS GRUPOS DE PRESSÃO FORMADOS POR MILITARES DA RESERVA E O PENSAMENTO ANTICOMUNISTA
}

\author{
Eduardo Heleno de Jesus Santos ${ }^{l}$ \\ e Vágner Camilo Alves ${ }^{2}$
}

\begin{abstract}
RESUMO
Este artigo apresenta alguns grupos de pressão formados por militares da reserva no Brasil, cuja linha ideológica tem forte discurso anticomunista. Esses grupos foram, em geral, constituídos após a redemocratização e uma de suas principais bandeiras é a defesa do status quo ante. Para melhor traçar a origem desses grupos, incluímos uma análise histórica para explicar como 0 anticomunismo ganhou expressividade dentro das Forças Armadas brasileiras.
\end{abstract}

Palavras-chave: Anticomunismo. Direita. Militares. Grupos de pressão.

\footnotetext{
1 Doutorando em Ciência Política na Universidade Federal Fluminense Brasil. eduheleno@gmail.com

${ }^{2}$ Professor Adjunto do Instituto de Estudos Estratégicos da Universidade Federal Fluminense. Brasil.vgcamilo@bol.com.br
} 


\title{
ANTICOMMUNIST THOUGHT AND PRESSURE GROUPS FORMED BY RETIRED MILITARY PERSONNEL
}

\begin{abstract}
This article discusses pressure groups formed by retired military personnel in Brazil, whose ideological line features a strong anticommunist discourse. In general, these groups were formed after the return to democracy, and one of their main goals is to defend the status quo ante. To better trace the origin of these groups, we included a historical analysis to explain how anticommunism gained expressiveness within the Brazilian Armed Forces.
\end{abstract}

Keywords: Anticommunism. Right-wing. Military. Pressure groups.

\section{INTRODUÇÃO}

s Forças Armadas não são um monólito. No século XX, os integrantes das
Forças Armadas dos países do Cone Sul experimentaram a influência de
uma série de correntes ideológicas que não raro causaram mudanças drásticas no que tange ao papel político e à função constitucional da instituição. Tais ideias, intrinsecamente associadas à um novo padrão de Estado e a um novo padrão de inserção das Forças Armadas, repercutiram nas fileiras com efeitos cruciais na instituição, nas relações civis e militares, na política e na sociedade. Os grupos de pressão política apresentados nesse artigo são frutos dessas interações entre diferentes correntes ideológicas tanto dentro das Forças Armadas, como no resto da sociedade, e estariam, hoje, definidos por seu posicionamento conservador de direita, com forte discurso anticomunista.

Os grupos a serem descritos nesse trabalho foram constituídos por oficiais da reserva de alto escalão (generais, coronéis e tenentes-coronéis), que vivenciaram o golpe militar de 1964 e o regime militar que a ele se seguiu. Estão distribuídos em todo o Brasil e buscam, através de mídia própria e visitas a unidades militares, difundir sua agenda para os integrantes das Forças Armadas e seus familiares. Como veremos, os grupos são em maioria formados por oficiais do Exército, instituição que teve preponderante papel político no Brasil no século passado.

Esses grupos de pressão, surgidos em sua maioria ao longo da transição para a democracia, teriam, como interesses, a preservação de certas prerrogativas das Forças Armadas, a continuidade de certos direitos auferidos no regime militar, o resguardo da noção de autoridade e status daquele período (tanto da corporação 
quanto do indivíduo a ela pertencente) e a manutenção dos valores tradicionais cristãos.

Podemos dizer que esse conservadorismo reúne características do pensamento conservador de direita, seja por sua contínua crítica à intervenção do Estado (exceto quando feita em prol das Forças Armadas), sua rejeição aos programas de distribuição de renda, e, especialmente, ao forte discurso maniqueísta e anticomunista, no qual qualquer entidade política de esquerda é considerada comunista e lesiva aos interesses do Estado e de seu braço armado, as Forças Armadas. A razão desse posicionamento leva em conta também um extremo ressentimento desses oficiais com parcela da sociedade pela maneira como as narrativas e discursos críticos ao golpe de 31 de março de 1964 e ao regime militar se tornaram hegemônicos.

Para entender a orientação desses grupos em torno de uma agenda conservadora e de direita, devemos pensar como o principal aspecto definidor do discurso desses grupos, 0 anticomunismo, ganhou influência nas Forças Armadas ao longo do século XX.

\section{UMA BREVE HISTÓRIA DO ANTICOMUNISMO NAS FORÇAS}

\section{ARMADAS BRASILEIRAS}

Como bem lembra Motta (2002), o anticomunismo surge em ondas, em especial depois da Revolução Russa de 1917, quando se cristaliza em realidade a ideia de um novo tipo de Estado. A União Soviética, surgida da destruição do Ancién Regime czarista, trouxe novidades e apreensões.

Seus reflexos no Brasil foram amplos. Setores da Igreja, informados dos relatos dos padres que viviam na antiga Rússia, passaram a ver com muito receio o Estado soviético. Entre os trabalhadores, a Revolução Russa inspirou greves e um novo movimento organizado que se traduziria na criação do Partido Comunista do Brasil, em 1922.

Nas Forças Armadas brasileiras, essa ideia foi bem recebida por alguns militares que viam na radical transformação política, econômica e social empreendida pelos revolucionários russos a inspiração para a tão desejada mudança social em um país atrasado. Nesse contexto, a aproximação de Luís Carlos Prestes com os simpatizantes do comunismo talvez seja o maior exemplo da atração exercida pelo comunismo entre os oficiais. 0 comunismo continuou ampliando sua influência naquela década, cujo final seria marcado pela grande 
crise global de 1929, momento em que a URSS mantinha seu crescimento, promovendo cada vez mais a proposta de ser a alternativa ao modelo liberal.

Porém, essa influência comunista nas fileiras seria reduzida no governo de Getúlio Vargas. 0 episódio conhecido como Intentona Comunista, ocorrido em 1935, serviu para o governo realizar uma forte campanha contra os comunistas dentro das Forças Armadas, recebendo inclusive apoio de importantes setores da Igreja Católica. Embora o governo tenha tratado a malograda insurreição como intento louco, por isso, intentona, esse episódio consistiu em uma série de sublevações que tinham o objetivo de tomar quartéis e importantes cidades.

Em 23 de novembro, militares do $21^{\circ}$ Batalhão de Caçadores $\left(21^{\circ} \mathrm{BC}\right)$, sediado em Natal, iniciaram uma sublevação para tomar a cidade. De maneira isolada e sem a coordenação central da Aliança Nacional Libertadora, eles conseguiram o controle da unidade militar e chegaram a organizar um governo local. Com o sucesso da tomada do quartel, no dia seguinte mais uma unidade militar, o $29^{\circ} \mathrm{BC}$, em Recife, sofreu uma sublevação. E, no dia 27, o $3^{\circ}$ Regimento de Infantaria e a Escola de Aviação, no Rio de Janeiro, foram alvo de uma tentativa de insurreição, rapidamente sufocada pelo governo (MOTTA, 2002, p. 188). Diante desse quadro de desordem, Vargas imediatamente retirou das Forças Armadas os militares identificados com 0 comunismo internacional. Com algumas modificações na Lei de Segurança Nacional e na Constituição de 1934, milhares de comunistas foram julgados, presos e excluídos das fileiras (MOTTA, 2002, p. 203).

A participação de oficiais e praças nos atentados e 0 culto à memória das vítimas da Intentona criado por Vargas ajudaram a disseminar por gerações a ideia de que ser comunista era ser traidor da pátria. Em 1938, no primeiro livro editado pela Biblioteca Militar, Em Guarda! Contra o Comunismo, destinado a difundir a historiografia oficial sobre a Intentona nos quartéis, há vários discursos de autoridades importantes da época, unânimes em condenar, de forma maniqueísta, o comunismo.

Em um dos textos do presidente Vargas, ele advertia que os "agentes da subversão e da desordem persistem com os seus planos diabólicos" (ESTADO MAIOR DO EXÉRCITO, 1938, p.23). Outro texto presente no livro, a "Carta pastoral e mandamento do episcopado brasileiro sobre o comunismo ateu”, de autoria do Cardeal Leme, o religioso sustentava que "o comunismo é intrinsecamente perverso", e que não era admissível que alguém colaborasse para destruir todos os fundamentos da fé cristã. (ESTADO MAIOR DO EXÉRCITO, 1938, p. 30). 
As notícias da Guerra Civil espanhola, ocorrida em 1936, e da Guerra Cristera no México, de 1929, também ajudaram a aumentar a intensidade dos protestos anticomunistas no livro. Segundo Rodeghero (2006, p.158), os relatos de pessoas que viveram na época criaram o imaginário no qual os comunistas seriam responsáveis pela perseguição e morte de católicos nesses eventos.

No discurso dessas autoridades e também nos jornais da época, notamos que os comunistas passaram a então representar uma imagem que mistura elementos de desobediência (em contraponto à hierarquia militar), de personificação do demônio (sensibilizando assim os católicos) e de ameaça ao poder. Mais do que isso, a lógica da fé se mesclou com o discurso do Estado (cada vez menos laico) e o reconheceu como integrante de uma civilização, a cristã, para se legitimar perante o comunismo. E parte dos militares, assim como parte da população, majoritariamente católica, naturalizaram essas ideias.

Com 0 fim da Segunda Guerra Mundial, com EUA e URSS como aliados, vencedores e cada vez mais desconfiados das ambições mútuas, houve mais uma onda anticomunista no mundo. No Brasil, de acordo com Rodeghero (2007, p. 62), uma manifestação da Igreja ocorrida em 14 de julho de 1945 na Praça da Sé em São Paulo, destinada agradecer a Deus o retorno dos soldados da guerra, foi permeada pelo discurso católico anticomunista, no qual foi defendida a equivalência entre o comunismo e 0 fascismo. No ano seguinte, relata a autora, um discurso do capitão Penna Botto, da Marinha, à rádio Educadora, ressaltaria a impossibilidade de tornar vigente a doutrina marxista em um país tradicionalmente cristão como o Brasil.

Em 1949, mesmo ano em que o Clube Positivista denunciava celebração da Páscoa Militar, o general José Pessoa, comandante da Zona Militar do Sul, escrevia uma recomendação à tropa a respeito das eleições presidenciais: ele alertava aos seus subordinados que as Forças Armadas não seriam ludibriadas pelos "obreiros diabólicos de documentos falsos", que feriram (na Intentona), a honra, a hierarquia e o decoro militar (0 GENERAL, 1949, p. 2).

Um detalhe mostra que 0 anticomunismo estava enraizado não somente no Exército, a Força Armada de maior participação política naqueles anos, mas também na Marinha: em 1952, o mesmo Penna Botto seria presidente da Cruzada Brasileira Anticomunista. E estaria também presente na recém criada Aeronáutica ${ }^{3}$, constituída por oficiais da Aviação do Exército, muitos deles veteranos da Segunda Guerra e com vivência em bases norte-americanas.

\footnotetext{
${ }^{3} 0$ Ministério da Aeronáutica foi criado em 20 de janeiro de 1941.
} 
Naqueles tempos, eram também anticomunistas os chefes de Polícia do Distrito Federal, entre eles, os coronéis do Exército, Batista Teixeira, Magassi Pereira e Amaury Kruel. Esse último comandaria, como general, o II Exército, no governo de João Goulart (RODEGHERO, 2007, p. 80).

A Guerra da Coreia seria um indicador da polarização ideológica existente no Clube Militar naquela época e, por extensão, nas Forças Armadas brasileiras. Um editorial da Revista do Clube Militar intitulado Considerações Sobre a Guerra da Coreia resultaria em polêmica na oficialidade, pois defendia que os Estados Unidos estavam realizando na verdade uma intervenção naquela região e que o Brasil deveria se manter neutro (CARVALHO, 2005, p. 112). 0 artigo escrito pelo capitão Humberto Freire de Andrade continha um sumário sobre outro artigo publicado pelo jornal francês La Tribune des Nations em que se criticava a intervenção americana e que esta teria como estratégia o massacre das populações civis (SODRÉ, 1968, p. 312). Após sua publicação, houve uma série de abaixoassinados em protesto ao teor do editorial.

Influenciada pelos primeiros anos da Guerra Fria, parte da oficialidade brasileira adotou 0 alinhamento com os Estados Unidos como postura ideal dentro do ambiente de bipolaridade que surgiu no pós guerra. Essa vertente encontrou apoio em setores mais conservadores da sociedade, entre os adeptos do anticomunismo e entre políticos que defendiam maior abertura econômica. A outra ala, defensora da neutralidade do país na agenda norte-americana, era interessada em um desenvolvimento pautado na intervenção do Estado em setores estratégicos e encontraria eco em setores nacionalistas e até mesmo na esquerda radical (ALVES, 2007, p. 156; PEIXOTO, 1980, p.77). Essa ala era representada pelos generais Estillac Leal e Julio Caetano de Horta Barbosa, vencedores da chapa que presidiu o Clube Militar entre 1950 e $1951{ }^{4}$

Para os liberais, os nacionalistas eram comunistas, para os nacionalistas, os liberais eram entreguistas (ALVES, 2007, p. 159). E tal adjetivação transbordava das discussões do Clube Militar e entornava nos tipos das gráficas dos jornais. Em um artigo do Correio da Manhã, o jornal mostrava preocupação com as

\footnotetext{
${ }^{4}$ Antônio Carlos Peixoto usa três critérios para classificar as correntes militares: desenvolvimento econômico, organização política e política internacional, no entanto ressalta as dificuldades intrínsecas para encontrar dicotomia bem definida no meio militar daquela época. Vágner Camilo Alves em seu estudo sobre a Coréia, utiliza os critérios de Antonio Carlos Peixoto, e divide as correntes militares como nacionalista e liberal, ressaltando, como Peixoto, a precariedade da tipologia diante do reducionismo. É comum também os adjetivos nacionalistas e entreguistas, embora os últimos não se reconhecessem dessa forma (PEIXOTO, 1980, p. 77).
} 
atividades do Clube Militar, "na medida em que afetam a ordem, a segurança e os compromissos da nação brasileira" e denunciava que "a agitação e o divisionismo são provocados pelos que querem transformar o Clube em uma ilha soviética" (PEIXOTO, 1980, p. 96). No editorial Disciplina e Autoridade, o jornal criticava a direção do Clube e chamava a atenção do governo para punir o grupo de oficiais simpáticos ao "imperialismo soviético" (DISCIPLINA, 1950, p. 4).

A corrente nacionalista acabaria perdendo a presidência do Clube Militar nas duas eleições que se sucederam e o debate sobre as grandes questões políticas teria espaço cada vez mais reduzido na revista do Clube. A corrente liberal, organizada em torno da Cruzada Democrática, encabeçada pelos generais Alcides Etchegoyen e Nelson de Melo, veteranos da FEB, venceu o pleito e tratou de promover a despolitização das edições da Revista (PEIXOTO, 1980, p. 96-98). Em 1954, com os generais Canrobert Pereira da Costa e Juarez Távora como candidatos, os liberais venceriam novamente.

Paralelamente, a Escola Superior de Guerra (ESG), criada em 1948 como um espelho do National War College dos Estados Unidos 5 , se tornara um centro irradiador da Doutrina de Segurança Nacional. Essa doutrina tem os seus primeiros conceitos desenvolvidos em 1949 e, segundo Svartman (2006, p. 190), fora a atualização, para os tempos de Guerra Fria, de "um repertório de classificação e de representação do mundo político e social” que já existia entre os militares brasileiros. Essa doutrina entrelaçou duas ideias-chave: segurança e desenvolvimento e foi uma construção coletiva dos oficiais que serviram à ESG. ${ }^{6}$ Com o passar dos anos, novos elementos foram inseridos àquela doutrina, em especial, os que foram trazidos, a partir de 1962, da influência norte-americana na contenção do comunismo nos governos Truman, Eisenhower e Kennedy (CHIRIO, 2012, p. 24).

Outra doutrina irradiada pela ESG, a Doutrina de Guerra Revolucionária, sofreu influência direta da experiência francesa na Argélia e na Indochina. No Brasil, a Doutrina de Guerra Revolucionária passou a ser conhecida em 1957, quando a revista Mensário da Cultura Militar publicou o artigo A Guerra

\footnotetext{
${ }^{5}$ Em 1927, o ministro da Guerra Pandiá Calógeras, que era civil, defendia a criação de um instituto de altos estudos políticos e estratégicos com presença de civis e militares. Naquele mesmo ano havia sido criado, na Inglaterra, Imperial Defense College, a primeira instituição desse tipo (MATTOS, 1977, p. 128).

${ }^{6}$ Svartman estranha que Golbery do Couto e Silva tenha sido alçado à fama de intelectual da Doutrina de Segurança Nacional, pois defende que o processo de criação da doutrina brasileira foi coletivo e um tanto quanto caótico.
} 
Revolucionária, um texto da Revue Militaire d'Information traduzido pelo tenente-coronel Moacyr Barcellos Potyguara. A Doutrina de Guerra Revolucionária visava um grau de controle das informações que só poderia ser realizado através da centralização do poder político e militar, em outras palavras, prescindia de forte intervenção militar no governo - o que servia não como uma prescrição do que fazer nas relações civis e militares brasileiras, mas como uma justificativa para aprofundar o que, naqueles tempos de intensa participação dos militares na política, já era feito (CHIRIO, 2012, p. 20; MARTINS FILHO, 2008, p. 43).

Com o golpe militar de 1964, mais de mil oficiais e praças, supostamente envolvidos com o comunismo seriam expulsos das fileiras ou transferidos para a reserva até 0 ano de 1968 (BORGES FILHO, 1994, p. 104). Como em 1935, a aproximação com 0 comunismo foi entendida como perigosa à hierarquia $\mathrm{e}$ disciplina, os dois pilares da instituição militar. Havia preocupação não somente com os oficiais de mesmo escalão que haviam apoiado o presidente deposto João Goulart e o governador Leonel Brizola, mas também com os praças (os marinheiros, em especial) que também prestavam apoio ao presidente.

Uma vez batida a última resistência armada por movimentos civis, a guerrilha do Araguaia, em 1973, a percepção que 0 comunismo ainda era uma ameaça foi ficando cada vez mais segmentada aos setores mais conservadores da instituição. E eram desses setores, ligados à comunidade de inteligência, que surgiam os alertas sobre 0 comunismo.

\section{IMPRENSA MILITAR E OS GRUPOS ANTICOMUNISTAS}

Ainda no início da década de 1970, surge uma publicação realizada por oficiais ligados à Escola Superior de Guerra, o tabloide Letras em Marcha, fundado e dirigido pelos coronéis Joaquim Victorino Portella Ferreira Alves e Neomil Portella Ferreira Alves, ambos da arma de artilharia. A inauguração do jornal ocorreu no dia 15 de novembro de 1970, no Círculo Militar de São Paulo, com a presença do então prefeito da cidade, Paulo Maluf.

Veterano da FEB, Joaquim Victorino foi um dos dois oficiais que entregaram pessoalmente intimações ao presidente Juscelino Kubistchek quando de seu retorno ao Brasil em outubro de 1965, para que prestasse depoimento no Inquérito Policial Militar que apurava a participação de esquerdistas no Instituto Superior de Estudos Brasileiros (ISEB). Ele também foi responsável por indiciar outro ex-presidente, Jânio Quadros, sobre o mesmo assunto. Anos mais tarde, seria conhecido informalmente como um dos "coronéis do IPM", ligado ao que se 
convencionou chamar de linha-dura, dentro do regime militar brasileiro (CHIRI0, 2012, p. 58-59). Entre 1966 e 1968, Joaquim Victorino faria parte do Corpo Permanente da ESG, escola que foi, como vimos, um centro irradiador da Doutrina de Segurança Nacional (PRESIDÊNCIA, 1966, p. 3). Em julho de 1984, já na reserva, receberia do presidente João Batista Figueiredo a promoção de Comendador da Ordem do Mérito Militar (MINISTÉRIO DO EXÉRCITO, 1984, p. 7).

Neomil Portella Ferreira Alves, o irmão de Joaquim Victorino, era formado em jornalismo pela PUC. Como major, serviu no $1^{\circ}$ Grupo de Artilharia de Costa em 1966, e em 1974, chegou, como tenente-coronel, à subdireção da Biblioteca do Exército. Foi transferido para reserva remunerada, como coronel, em 30 de dezembro de 1980. Em 1984, foi agraciado com a Ordem do Mérito Militar, no nível oficial (MINISTÉRIO DO EXÉRCITO, 1984, p. 7).

Embora tenha sido fundado em São Paulo, a sede do jornal funcionava em Copacabana, no Rio de Janeiro. Participavam do Letras em Marcha oficiais alunos do curso de Comunicação Social do Exército, militares já na reserva, como os oficiais generais Aurélio de Lyra Tavares (integrante da Junta Militar que antecedeu o governo Médici), Carlos Alberto Fontoura (ex-chefe do SNI no governo Médici), João Paulo Moreira Burnier (notório conspirador da Força Aérea), Sebastião Ramos de Castro (ex-assessor, no SNI, do general Figueiredo), Carlos de Meira Mattos (um dos formuladores da geopolítica brasileira na ESG); os coronéis Antonio Erasmo Dias (ex-secretário de Segurança Pública de São Paulo, responsável pela invasão à PUC em 1977), Hélio Ibiapina de Lima (um dos coronéis do IPM), Renato Brilhante Ustra (irmão do também coronel Ustra, acusado de ser torturador no DOI CODI), entre outros.

Havia também, entre os civis, artigos de intelectuais notórios como Gilberto Freyre e Pedro Calmon. E parlamentares, como os ex-deputados Emílio Antonio Mallet de Souza Aguiar Nina Ribeiro (ARENA) e Anísio Rocha (MDB), e o vereador Wilson Leite Passos (um dos fundadores da UDN, militante da ARENA, do PDS, entre outros). Cabe também destacar que havia integrantes dos serviços de inteligência e ex-alunos da ESG participando do jornal.

Pode-se dizer que o Letras em Marcha teve certa influência na máquina burocrática militar. 0 periódico chegou a ser anexado a Noticiário do Exército, boletim oficial da Instituição e contava com anúncios do Ministério da Aeronáutica, da Carteira Hipotecária da Aeronáutica, do Senai e da Sharp (SANTOS, 
2009a, p. 17). Um de seus administradores era 0 marechal Denys ${ }^{7}$, e graças à intervenção dele, no início da década de 1980, o jornal, que quase fechou por falta de recursos, recebeu um aporte de publicidade do Banco Nacional, controlado pelo ex-governador de Minas, Magalhães Pinto (BOECHAT, BOJUNGA, 1987, p. 12). Além disso, o sistema de distribuição recebia apoio dos oficiais da $5^{\text {a }}$ Seção, de Relações Públicas e dos chefes de serviços de correios dos grandes comandos. Dos 15 mil exemplares do jornal, 70\% eram distribuídos para a tropa.

Com seu discurso anticomunista, o jornal era considerado pelos grandes imprensa como o porta-voz da linha-dura dos militares. Parte de seus artigos foram trazidos à baila pela imprensa ao longo do período de redemocratização devido ao teor radical de seus discursos. Para se ter uma ideia, em 1981, um mês depois do atentado à bomba no Rio Centro do qual foi imputada a culpa aos integrantes dos órgãos de inteligência, um editorial do Letras em Marcha $\left(\mathrm{n}^{0} 115\right)$ dava a entender que tal responsabilização era uma campanha da imprensa, supostamente infiltrada por esquerdistas, para "acabar com os órgãos de informações, em especial, com os DOI CODI” (JORNAL, 1981, p.4). Três anos depois, o jornal fez campanha para seus leitores, em geral, militares, associando o candidato Tancredo Neves ao presidente argentino Raul Alfonsín e taxando-o de comunista e kerenskiável (JORNAL, 1984, p. 2).

Em 1989, com a aproximação da primeira eleição geral para presidente da República, o jornal preparou um suplemento político de dez páginas. Dessas dez páginas, oito eram dedicadas, sempre em tom alarmista, a fazer campanha contra o partido dos Trabalhadores e o seu candidato, Luís Inácio Lula da Silva (SANTOS, 2009a, p. 18).

0 jornal Letras em Marcha iniciou lentamente o seu processo de encolhimento em 1987, com a morte do coronel Neomil Portella, vindo a deixar de circular no ano 2000, após o falecimento do coronel Joaquim Victorino Portella. Entre 1988 e 2005, um novo jornal, o Ombro a Ombro, fundado por excolaboradores do Letras em Marcha, os coronéis da reserva Pedro Schirmer e Antonio Gonçalves Meira, acabou servindo como tribuna militar para vários grupos de pressão política formados por oficiais da reserva. Esse jornal, também com sede no Rio de Janeiro, tinha tiragem similar ao Letras em Marcha, embora buscasse ter uma proposta mais plural dentro das linhas conservadoras nas Forças Armadas. Outro tabloide, de menor repercussão para a grande imprensa,

\footnotetext{
${ }^{7}$ Odílio Denys foi ministro da Guerra no governo de Jânio Quadros. Apesar de ter participado das principais articulações militares, deixou a vida política em 1964.
} 
era o preparado pelo Grupo 31 de Março, o Informativo 31 de Março, que era distribuído para uma lista de oficiais. Esse grupo, com sede na capital fluminense, foi criado pelo general de divisão R/1 Henrique Carlos de Assumpção Cardoso e fundado em 15 de novembro de 1988, devido à preocupação com uma provável vitória de Lula nas eleições de 1989 (SANTOS, 2009a, p. 23).

Do período que vai de 1988 até 1998, em que se sucedem as primeiras eleições da Nova República, a grande crise institucional no governo Collor, a transição conduzida pelo vice Itamar Franco e os dois mandatos de Fernando Henrique Cardoso, surgem, espalhados pelo Brasil, novos grupos que terão como objetivo não somente manter a propaganda anticomunista, mas fazer pressão para uma mudança na política do país. Alguns desses grupos eram formados, assim como o jornal Ombro a Ombro, por antigos colaboradores do Letras em Marcha.

0 Guararapes, do Ceará e o Araucária, do Paraná, foram dois grupos que se destacaram neste período por divulgar manifestos pedindo um golpe de Estado para estancar a crise política e econômica que afligia o país. ${ }^{8}$ Em que pese nem todos os grupos formados no período pregarem esta solução radical, não raro enalteciam os anos do regime militar como uma época em que os escândalos políticos não ocorriam.

0 grupo Guararapes, fundado em 1991, em Fortaleza, surgiu por causa da percepção negativa de seus integrantes sobre a presença de políticos esquerdistas no governo Collor e devido à incerteza sobre o rumo que poderiam tomar os acontecimentos. Com o impeachment do presidente, um dos líderes fundadores do Guararapes, o general da reserva Francisco Batista Torres de Mello, acabou sendo convidado para integrar a Comissão de Investigação do Senado composta para apurar as irregularidades do antigo governo. Atualmente, eles mantém um site na internet e costumam preparar manifestos de crítica à situação da Forças Armadas (SANTOS, 2009a, p. 25).

0 grupo Araucária, dirigido pelo coronel da reserva Mario Stadler, foi criado em 31 de março de 1993, na cidade de Curitiba e teve repercussão na imprensa na época devido às polêmicas declarações de seu líder, vindo a diminuir suas atividades depois das eleições de 1994.

0 grupo Inconfidência, fundado em Minas Gerais em 1993, é outro que surge nesse período. Presidido pelo coronel da reserva Claudio Miguez, esse grupo

\footnotetext{
${ }^{8} \mathrm{Na}$ pesquisa realizada para 0 mestrado, foi contabilizado o surgimento de treze grupos neste período. Porém, nem todos pregavam o golpe de Estado. Entre 1988 e 2008, haviam surgido ao total 22 grupos.
} 
busca defender o status quo ante. Desde 1994, eles passaram a produzir o seu próprio diário impresso, o Inconfidência, no qual defendem a permanência dos valores católicos e fazem propaganda anticomunista e de oposição aos governos de esquerda. A publicação do grupo contou, até 2011, com anúncios do Sistema de Financiamento do Fundo Habitacional do Exército (FHE/POUPEX), da administradora de fundos de previdência privada Grêmio Beneficente dos Oficiais do Exército (GBOEx) e do Clube Militar, além da contribuição dos 500 assinantes e 200 associados. A tiragem, que em anos anteriores chegou a 20 mil exemplares, atualmente atinge, no máximo, sete mil jornais. Eles são distribuídos para as unidades militares do Exército, para os comandos da Aeronáutica e Marinha e para as escolas públicas estaduais e municipais de Minas Gerais. ${ }^{9}$ Nos meses de março, agosto e novembro, essa tiragem costuma ser ampliada, em função das edições históricas do 31 de março, Duque de Caxias e Intentona Comunista, destinadas ao público jovem das escolas de formação (SANTOS, 2009a, p. 39-40).

$\mathrm{Na}$ leitura dos textos do grupo, está explícita a ideia de que 0 principal motivo para o julgamento desfavorável aos militares, tanto em relação à 1964 , como ao regime que seguiu, é o revanchismo. Ainda em relação à memória, 0 grupo participa e organiza encontros com militares da ativa no Círculo Militar de Belo Horizonte e outras unidades da $4^{\mathrm{a}}$ Região Militar. A permeabilidade do grupo nestes locais pode ser interpretada como resultado dos laços de camaradagem entre os oficiais, principalmente os mais velhos, cuja aproximação é facilitada pela existência de valores e vivências comuns.

Outra entidade que realiza atividades em quartéis e cuja sede foi, por muito tempo, localizada no Clube Militar no Rio de Janeiro ${ }^{10}$, é o grupo Terrorismo Nunca Mais (Ternuma). Eles surgiram em 1995 e sua origem como grupo de pressão era servir como contraponto às versões do grupo Tortura Nunca Mais veiculadas na imprensa assim como contestar a política de Direitos Humanos promovida pelo governo de Fernando Henrique Cardoso. Dos eventos que ajudaram a conformação desse grupo, podemos destacar a retirada do coronel Armando Avólio Filho do cargo de adido militar na Inglaterra, por acusação de tortura no regime militar, e os estudos para indenização das vítimas do regime, entre elas o capitão Carlos Lamarca. Por outro lado, a possibilidade de reabertura do processo que envolvia o coronel Carlos Alberto Brilhante Ustra, acusado em

\footnotetext{
${ }^{9}$ Conforme entrevista posterior com o coronel Miguez e informações colhidas em Maier (2006).

${ }^{10}$ Em 2011, o Ternuma deixou a sede no Rio de Janeiro, e centralizou suas atividades em Brasília, onde funcionava a sua sucursal. No entanto, o grupo continua organizando e participando de atividades no Clube Militar sobre 031 de março de 1964.
} 
1985 pela atriz Bete Mendes de tê-la torturado nos porões do DOI-CODI, era um sinal de alerta para esses militares da reserva.

Tendo como patrono o ex-presidente Médici, a entidade foi formalizada no dia 25 de julho de 1998, no aniversário de 32 anos do atentado à bomba no aeroporto de Guararapes (SANTOS, 2009a, p. 46). O Ternuma organiza seminários, reuniões e palestras cujos principais temas se referem à memória do regime militar. Segundo o coronel aviador Juarez de Deus Gomes da Silva, que fora presidente da entidade por dez anos: "O público-alvo do grupo é a juventude; não nos interessa dizer o que pensamos aos que pensam como nós". Pode-se incluir nessa juventude, a parcela de jovens oficiais, uma vez que o grupo organiza palestras em quartéis, como o do Comando Militar do Leste, no Rio de Janeiro, para defender suas versões da história (SANTOS, 2009a, p. 48).

0 componente político de suas atividades pode ser notado pelo seguinte episódio: em 2009, uma ficha falsa da então candidata Dilma Rousseff, supostamente feita no tempo em que atuara na guerrilha e cuja autoria foi atribuída ao Departamento de Ordem Político Social (DOPS), foi veiculada pelo site. Essa mesma ficha seria estampada na capa do jornal Folha de São Paulo, com grande repercussão, devido à corrida presidencial. Dois dias depois, o jornal reconheceu que tratava-se de um documento falso.

\section{CONCLUSÃo}

Os grupos de pressão política formados por militares da reserva apresentados nesse trabalho não traduzem a totalidade do pensamento dentro das Forças Armadas. Como vimos, a instituição é composta de várias correntes, como espelho da sociedade, e os grupos sumariamente aqui descritos espelham mais as percepções existentes no período da Guerra Fria que o momento atual. Isso porque essas entidades são constituídas por militares da reserva que viveram 0 regime militar e não por oficiais da ativa. Além disso, há uma grande dificuldade de renovação das lideranças e dos quadros, o que faz com que alguns destes grupos deixem de existir ou se aglutinem em algum outro grupo.

De certo que o tratamento dado pelos governos e pelas cúpulas militares aos oficiais simpatizantes da esquerda em 1935 afetou muito a imagem do Exército como instituição, aproximando-o das forças conservadoras de direita. Uma nova aproximação foi feita na década de 1950, sob forte influência da Guerra Fria, quando o Clube Militar passou a ser presidido pelos conservadores de direita e o debate político naquela entidade se reduziu. Paralelamente, a ESG se 
desenvolvia como difusora de uma nova mentalidade aos oficiais, que aproximava os núcleos conservadores da instituição militar e que acabou por promover uma lógica intervencionista e anticomunista. Na década de 1960, com a nova polarização nas fileiras e o consequente golpe de 31 de março de 1964, um novo expurgo afetaria 1.228 militares até 1968 e reduziria sobremaneira a existência de diferentes linhas de pensamento dentro da instituição.

A criação do jornal Letras em Marcha em 1970 por oficiais ligados à ESG mostrou a capacidade de organização dos militares que defendiam um pensamento conservador de extrema direita, com forte discurso anticomunista. Esse discurso continuou fazendo, em maior ou menor grau, parte da essência dos grupos de pressão política aqui apresentados, mesmo no pós Guerra Fria, com 0 fim da URSS. Esse componente ideológico acaba sendo a identidade pela qual esses grupos criticam os governos e procuram defender seus interesses, que vão desde 0 reconhecimento pelos feitos realizados no regime militar ao restabelecimento do papel exercido pelos militares na política, passando também pela defesa dos militares acusados de terem praticado tortura na repressão.

Esses grupos buscam se posicionar como trincheiras em uma batalha pela memória do golpe e do regime militar, no qual os discursos the valem como armas e cujo objetivos são os corações e mentes do público mais jovem.

Sem dúvida, a emergência desses grupos no contexto democrático está ligada ao novo status quo, em que forças políticas progressistas de esquerda assumem um papel cada vez maior na política, com a consequente promoção de uma agenda na qual temas como os Direitos Humanos e a Política de Memória são importantes. Relacionam-se também à transformação da memória social ocorrida ao longo da transição democrática, em que os setores marginalizados e perseguidos durante o regime militar foram ganhando voz, assumindo e definindo, gradativamente, as versões hegemônicas sobre o período.

Marcados pelo ressentimento, receosos do revanchismo e atrelados à lógica anticomunista, esses grupos de pressão política formados por militares da reserva representam, por estarem afastados da instituição e buscarem a atenção dos militares mais jovens, sinais de que as Forças Armadas brasileiras e a sociedade vão seguindo outro caminho, mais adaptado aos tempos da democracia. Como as Forças Armadas não são um monólito, embora haja correntes que difundam esse discurso dentro da corporação militar, elas estão imersas a tantas outras correntes de pensamento dentro da instituição e da sociedade. 


\section{REFERÊNCIAS}

ALVES, Vágner Camilo. Da Itália à Coréia: decisões sobre ir ou não à guerra. Rio de Janeiro: Ed. Iuperj: Ed.UCAM; Belo Horizonte: Ed. UFMG, 2007.

BOECHAT, Ricardo; BOJUNGA, Claudio. Em marcha contra a esquerda. Jornal do Brasil, 5 de junho de 1987. Caderno B, p. 12.

BORGES FILHO, Nilson. Os militares no poder. São Paulo: Acadêmica, 1994.

CARVALHO, José Murilo de. Forças Armadas e Política no Brasil. Rio de Janeiro: Jorge Zahar, 2005.

CHIRIO, Maud. A política nos quartéis: revoltas e protestos de oficiais na ditadura militar brasileira. Rio de Janeiro: Zahar, 2012.

DISCIPLINA e Autoridade. Correio da Manhã, 23 de dezembro de 1950, p.4. [editorial].

ESTADO MAIOR DO EXÉRCITO. Em guarda contra o comunismo. Rio de Janeiro: Biblioteca Militar, 1938.

JORNAL acusa imprensa de fazer campanha contra órgãos de informações. Jornal do Brasil, 5 de junho de 1981, p. 4.

JORNAL ligado a militares não combate mais Tancredo. Jornal do Brasil, 30 de dezembro de 1984, p. 2.

MAIER, Félix. Memória. 2006. Disponível em: $<$ http://www.usinadeletras.com.br/exibelotexto.php?cod=3136\&cat=Discursos $>$. Acesso em: 30 jan. 2013.

MARTINS FILHO, Jose Roberto. A influência doutrinária francesa sobre os militares brasileiros nos anos de 1960. Revista Brasileira de Ciências Sociais, São Paulo, v. 23 , n. 67 , jun. 2008 .

MINISTÉRIO DO EXÉRCITO. Decreto de 23 de julho de 1984, Diário Oficial da União de 25 de julho de 1984, p. 7. Seção 1.

MOTTA, Rodrigo P. S. Em guarda contra o perigo vermelho. São Paulo: Perspectiva: FAPESP, 2002.

0 CASO da Revista do Clube Militar. Correio da Manhã, 16 de dezembro de 1950, p.1. [editorial].

0 GENERAL José Pessoa faz uma recomendação sobre a campanha política. Correio da Manhã, 22 de março de 1949, p.2. 
PRESIDÊNCIA da República, Estado-Maior das Forças Armadas. Decreto de 27 de setembro de 1966. Diário Oficial da União, 28 de setembro de 1966, p. 3. Seção 1 .

PEIXOTO, A.C. O Clube Militar e os confrontos no seio das Forças Armadas (1945-1964). Tradução de Otávio Alves Velho. In: ROUQUIÉ,A (Coord).Os Partidos Militares no Brasil.Rio de Janeiro: Record, 1980.

RODEGHER0, Carla Simone. Capítulos da guerra fria: o anticomunismo brasileiro sobre o olhar norte-americano (1945-1964). Porto Alegre: EdUFRGS, 2007.

ROUQUIÉ, Alain (Coord.). Os partidos militares no Brasil. Rio de Janeiro: Record, 1980.

SANTOS, Eduardo Heleno de Jesus. Extrema direita, volver! Memória, ideologia e política dos grupos formados por civis e os militares da reserva. 2009. Dissertação (Mestrado em Ciência Política) - Universidade Federal Fluminense, Rio de Janeiro, 2009a.

SANTOS, Eduardo Heleno de Jesus. Memória dos militares sobre as ditaduras do cone sul: uma perspectiva comparada acerca das iniciativas contra 0 esquecimento. In: $33^{\circ}$ ENCONTRO ANUAL DA ANPOCS, 2009, Caxambu. Anais. Caxambu, 2009b.

SODRÉ, Nelson Werneck. História Militar do Brasil. Rio de Janeiro: Civilização Brasileira, 1968.

SVARTMAN, Eduardo Munhoz. Guardiões da nação: formação profissional, experiências compartilhadas e engajamento político dos generais de 1964. 2006. Tese (Doutorado em Ciência Política) - Universidade Federal do Rio Grande do Sul, Porto Alegre. 